\title{
A New Rechargeable Battery Design Based on Magnesium and Persulfate*
}

\author{
Robert S. Disselkamp \\ Solis Research, Richland, Washington, USA \\ Email: thegreenphd@gmail.com
}

Received 4 March 2015; accepted 19 March 2015; published 24 March 2015

Copyright (C) 2015 by author and Scientific Research Publishing Inc.

This work is licensed under the Creative Commons Attribution International License (CC BY).

http://creativecommons.org/licenses/by/4.0/

(c) (i) Open Access

\begin{abstract}
A battery concept based on the chemical system of magnesium (anode) and persulfate (cathode) is presented. A complete procedure is given to prepare the battery for testing, although no experimental data is presented herein. The similarities of this system to a well-tested $\mathrm{Li}|| \mathrm{LiFePO}{ }_{4} \mathrm{system}$ lend strong credibility to the concept, and the estimated performance characteristics presented. The advantages of this design include the following many areas. First, inexpensive, and available, battery reagents exist. Second, by analogy to the lithium ion battery for which comparisons are made, the full fabrication process for battery separator design is known and efficient; and both the $\mathrm{kJ} / \mathrm{kg}$ and Amps/kg values are estimated to be substantially larger than the lithium ion battery (e.g., $\mathrm{Li}|| \mathrm{LiFePO}_{4}$ ) experimental design. Finally, flammability of the $\mathrm{Mg}|| \mathrm{MgS}_{2} \mathrm{O}_{8}$ system can be expected to provide less of a potential flammability concern, compared to comparable lithium ion batteries. This is because lithium metal, as with any alkali metal, is aggressively flammable even under reduced moisture environments. The proposed magnesium persulfate battery calculated metrics yield an improvement of $194 \%$ greater output power $\left(\mathrm{W} / \mathrm{cm}^{2} \cdot \mathrm{kg}\right)$, and $154 \%$ greater stored energy (MJ/kg) than state-of-the-art lithium iron phosphate batteries.
\end{abstract}

\section{Keywords}

Magnesium Persulfate, Rechargeable Battery, Low Flammability, Energy Storage

\section{Introduction}

Rechargeable battery technology offers promise as a means to store energy for a wide variety of applications. Possible uses include: peak shaving and renewable energy storage stations; electric car and truck energy storage; electronic devices such as computers and cell phone energy storage; and small battery applications (e.g., 9 V, $1.5 \mathrm{~V}$ ) such as for watches, toys, games, etc. In this list from the large to small storage applications, it is seen the

${ }^{*}$ Magnesium persulfate rechargeable battery. 
energy storage can range from more than $10 \mathrm{MJ}$ to less than $1.0 \mathrm{~kJ}$. To date, there does not exist a rechargeable battery concept that is suited to a broad range of energy storage capabilities such as these. The reason for existing rechargeable design limitations are due to the high cost of materials, such as lithium and other expensive metals [1] and sophisticated fabrication methods [2]-[5] in order to circumvent the low specific energy storage values $(\mathrm{kJ} / \mathrm{kg})$, and unacceptable performance of battery output (e.g., electrical performance) as in low values of Amps/kg.

In prior lithium ion battery (LIB) work by Nitta and Yushin [1], they examined a variety of pure metal composites, or their carbon composites (e.g., C, Si, Ge, Sn, Pb, P, As, Sb, Bi, Al, Ga, Zn, and Ag). They also examined a Li-Mg alloy here in their lithium ion battery study. In the latter study, their Li-Mg alloy exhibited a low lithiation potential of $0.05 \mathrm{~V}$ (e.g., a desirable result), but a somewhat high delithiation potential of $0.24 \mathrm{~V}$ (an undesirable result). Aside from this reference to magnesium as an Li-Mg anode LIB alloy material, there were no other information found to the use of magnesium alone (e.g., pure metal) in reference to a rechargeable battery employing magnesium-persulfate system.

A wide variety of unique and sophisticated LIB fabrication methods have been utilized. These include: work by Lee et al. [2] using cation-disordered oxides; a study by Mohanty et al. [3] on Li-Mn-rich oxides illustrating a unique phase change; a study by Kennedy et al. [4] employing nanowire LIB anodes demonstrating extended cycling more than 1000 times; and work by Li et al. [5] that examined the Li-Ni-Co-Mn-O atomic layer deposition.

\section{Proposed Experimental Fabrication Method}

Although no prototype battery was constructed, the fabrication method is identical to a method employed for a $\mathrm{Li} \| \mathrm{LiFePO}_{4}$ rechargeable battery design recently published [6]. The only difference is the chemical system is changed to $\mathrm{Mg} \| \mathrm{MgS}_{2} \mathrm{O}_{8}$. Reference to that publication is made for experimental details. Here, only the experimental differences are highlighted.

The method of fabrication of the magnesium metal anode is easy compared to lithium, as the metal can be (acid) polished in ambient air, or with more care under an inert gas environment to eliminate the possibility of a surface oxide layer.

The $\mathrm{MgS}_{2} \mathrm{O}_{8}$ cathode material requires more preparation attention, as the starting reagent for this is solid persulfuric acid, $\mathrm{H}_{2} \mathrm{~S}_{2} \mathrm{O}_{8}$ (s). The persulfuric acid can be dissolved in a suitable organic solvent (e.g., one with a large electrochemical window), such as methylene chloride, into which is added magnesium hydroxide, Mg $(\mathrm{OH})_{2}$. Either the monohydrate, or anhydrous, magnesium hydroxide is preferred. This is because the desired precipitated product, $\mathrm{MgS}_{2} \mathrm{O}_{8}$, has a redox potential greater than the water redox potential breakdown voltage of

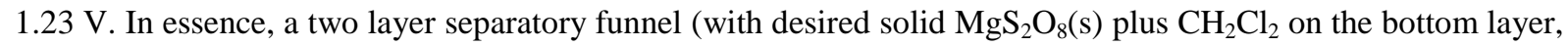
and aqueous top layer) is separated, and the organic solvent is dried (under vacuum) from the pure $\mathrm{MgS}_{2} \mathrm{O}_{8}(\mathrm{~s})$. Other solvents may be preferable to methylene chloride. Further purification of $\mathrm{MgS}_{2} \mathrm{O}_{8}(\mathrm{~s})$ by recrystallization is an option, depending upon initial purity obtained.

The third battery component necessary to fabricate, and one that is critical to battery performance, is the battery separator. As referenced above, the work by Zhu et al. [6] describes the use of gel polymer doped glass fiber mats in a lithium ion battery experiment. With only minor modifications to the chemical system here this same synthesis can be applied here. The gel is comprised of poly(vinylidene fluoride) (PVDF) with a $\mathrm{Mg}\left(\mathrm{PF}_{6}\right)_{2}$ $(1 \mathrm{M})+$ ethylene carbonate-dimethyl carbonate-ethyl methyl carbonate (1/1/1 weight ratio solvent system). Fortunately, a supplier of magnesium diflurophosphate is American Elements (www.americanelements.com), hence this approach a straightforward adaptation of the method of Zhu et al. [6] that utilized LiPF $\mathrm{F}_{6}$ at $1 \mathrm{M}$ in the organic solvent mixture, instead. Also important is the major impurity in $\mathrm{Mg}\left(\mathrm{PF}_{6}\right)_{2}$ is sulfate, the reduction product of persulfate- an additional benefit to use of this electrolyte. Other suppliers, or synthesis of $\mathrm{Mg}\left(\mathrm{PF}_{6}\right)_{2}, \mathrm{may}_{\mathrm{be}}$ possible, but have not been explored. The full synthetic procedure of the PVDF-glass fiber mat (GFM) procedure is straight forward, but multi-stepped and fully detailed. Of significance here is the fact that the PVDFGFM separator has a wide electrochemical window (ECW) of $4.8 \mathrm{~V}$ [6], which is large enough for the work of Zhu et al. [6], but also for the larger ECW here of the $\mathrm{Mg} \| \mathrm{MgS}_{2} \mathrm{O}_{8}$, described below.

A mention can be made regarding the specifics of the fabrication method of the proposed battery type presented here. Certainly additional work is needed in choosing particle size domains and thicknesses of the individual (anode, membrane, and cathode) construction regions of the battery components. However, these details, although important, are not speculated upon here, but are solvable by a disciplined approach to its optimization. 


\section{Rechargeable Battery Theory and Feasibility}

\subsection{REDOX Chemistry}

The oxidation-reduction reactions of the $\mathrm{Mg} \| \mathrm{MgS}_{2} \mathrm{O}_{8}$ system are given below. Standard potential data was taken from Bard et al. [7].

$$
\begin{array}{r}
\mathrm{Mg} \rightarrow \mathrm{Mg}^{2+}+2 \mathrm{e}^{-} \quad \text { - oxidation }-\mathrm{E}^{\mathrm{o}}(\mathrm{Ox} .)=+2.356 \mathrm{~V} \\
\mathrm{~S}_{2} \mathrm{O}_{8}^{2-}+2 \mathrm{e}^{-} \rightarrow 2 \mathrm{SO}_{4}^{2-} \quad-\text { reduction }-\mathrm{E}^{\mathrm{o}}(\text { Red. })=+1.963 \mathrm{~V} \\
\text { Total: } \mathrm{Mg}+\mathrm{S}_{2} \mathrm{O}_{8}^{2-} \rightarrow \mathrm{Mg}^{2+}+2 \mathrm{SO}_{4}^{2-} \quad \mathrm{E}^{\mathrm{o}}(\text { Tot. })=+4.319 \mathrm{~V}
\end{array}
$$

The potentials for reactions (1)-(3) are based on aqueous standard state data [7], and so actual potentials in the organic matrix, as proposed here, may vary somewhat but are not expected to be reduced by more than $5 \%$. The redox potential of $4.3 \mathrm{~V}$ is seen to be below the ECW of the organic matrix system chosen, as described above, demonstrating its compatibility.

\subsection{Voltage-Ionic Conductivity-Areal Power Performance Comparison}

There are many considerations to take into account when making as estimate of the electrical performance of the magnesium persulfate battery. First, the migration of $\mathrm{Li}^{+}$versus $\mathrm{Mg}^{2+}$ in the battery must be made. As studied by Malik et al. [8] for the $\mathrm{LiFePO}_{4}$ system, the size of the microcrystalline $\mathrm{LiFePO}_{4}$ domains and their defects affect $\mathrm{Li}^{+}$diffusion. Most notably here, however, is the expected similarity between the $\mathrm{LiFePO}_{4}$ and $\mathrm{MgS}_{2} \mathrm{O}_{8}$ domains that could be tailored to be comparable in size. Hence, these microcrystalline domains alone need not lead to differences in $\mathrm{Li}^{+}$and $\mathrm{Mg}^{2+}$ diffusion. Second, the implicit differences between the $\mathrm{Li}^{+}$and $\mathrm{Mg}^{2+}$ masses, collision diameters, and charges, can be taken into account according to Equation (4).

$$
D \approx \frac{C}{\sqrt{M} s^{2}}
$$

where $D$ is the diffusion constant $\left(\mathrm{cm}^{2} / \mathrm{s}\right), c$ is the ion charge, $M$ is the ion mass (amu), and $s$ is the collision cross-section $\left(\mathrm{nm}^{2}\right)$. The full expression of diffusion is unnecessary here, as the additional terms are constant between $\mathrm{Li}^{+}$and $\mathrm{Mg}^{2+}$, but can be found elsewhere [9]. Table 1 below lists the parameters for these two ions.

The collision areas were based on ion radii of R. Hancock, Acc. Chem. Res. 1990, 23, 253-257 [10]. Computing the relative diffusion constant ratio between the $\mathrm{Mg}^{2+}$ and $\mathrm{Li}^{+}$ions, namely $\mathrm{D}\left(\mathrm{Mg}^{2+}\right) / \mathrm{D}\left(\mathrm{Li}^{+}\right)$, results in a value of 1.12. Hence, the $\mathrm{Mg}^{2+}$ diffusion constant is $12 \%$ larger than the $\mathrm{Li}^{+}$ion, largely because of it having twice the charge, despite having a larger square of its mass term. This $12 \%$ enhancement will be utilized in further calculations below, as it increases the ionic conductivity by this factor.

The rechargeable battery power output is given the formula:

$$
P=\frac{K V^{2} d}{10 A}
$$

where $P$ is the power (W), $K$ is the ionic conductivity $(\mathrm{mS} / \mathrm{cm}), V$ is the flat discharge voltage, $d$ is the PVDFGFM electrolyte gel polymer glass fiber mat thickness in microns $(175 \mu \mathrm{m})$, and $A$ is the test area of the disk (e.g., cross-sectional area, $\mathrm{cm}^{2}$ ). The difference between the theoretically computed battery voltage and flat discharge voltage is a measure of the polarization losses. This information can be summarized in Table 2.

The result of the calculations in Table 2 are that the flat discharge power of the proposed $\mathrm{Mg}|| \mathrm{MgS}_{2} \mathrm{O}_{8}$ re-

Table 1. Comparision of parameters of magnesium and lithium ions yielding differences in their diffusion constants.

\begin{tabular}{ccc}
\hline Parameter & $\mathrm{Mg}^{+2}$ Ion & $\mathrm{Li}^{+}$Ion \\
\hline C-ion charge & +2 & +1 \\
M-ion mass (amu) & 24.3 & 6.9 \\
S-collision area $\left(\mathrm{nm}^{2}\right)$ & 0.0670 & 0.0707 \\
\hline
\end{tabular}


chargeable battery of $173 \mathrm{~W} / \mathrm{cm}^{2}$ is $42 \%$ larger compared to the battery in this study, that is representative of existing $\mathrm{LiFePO}_{4}$ battery performance. This is an appreciable gain.

\subsection{Power and Energy Performance Comparison}

The conversion of power performance of the last section, into specific power performance, is readily achieved by noting the following. The power performance of W/ $/ \mathrm{cm}^{2}$ is actually $\mathrm{W} / \mathrm{cm}^{2} \cdot \mathrm{mol}$, where the mole refers to one reaction mole for either the $\mathrm{Li}|| \mathrm{LiFePO}_{4}$, or $\mathrm{Mg} \| \mathrm{MgS}_{2} \mathrm{O}_{8}$ reactions. The mass of the lithium iron phosphate system (for both half-reactions) is $164.6 \mathrm{~g} / \mathrm{mol}$, whereas the magnesium persulfate system has a mass of 240.8 $\mathrm{g} / \mathrm{mol}$. Because the proposed magnesium system is a two electron system, and the lithium system is a one electron system, the result is the magnesium battery mass is only $73 \%$ that of the lithium system per mole of electrons tranferred.

Using this $73 \%$ reduction in battery mass, this translates into the specific power increase $\left(\mathrm{W} / \mathrm{cm}^{2} \cdot \mathrm{kg}\right)$ of the magnesium persulfate system divided by the lithium iron phosphate system to be $194 \%$ (nearly twice as efficient).

Of additional interest, is the specific energy storage capability. For example, using the flat discharge voltages of Table 2, the masses in $\mathrm{kg} / \mathrm{mol}$ for each system, and Faraday's constant can yield values of stored energy in $\mathrm{MJ} / \mathrm{kg}$. This calculation has shown that the magnesium persulfate system has a value $154 \%$ larger than that of the lithium iron phosphate battery. A summary of the property comparison between the two battery systems is given in Table 3 below.

In every category in Table 3 it is seen that the proposed magnesium persulfate battery concept is superior to the currently used lithium iron phosphate battery. It must be noted that the reason why percentages are listed in

Table 2. Comparison of $\mathrm{Li}_{\|} \mid \mathrm{LiFePO}_{4}$ and estimated $\mathrm{Mg} \| \mathrm{MgS}_{2} \mathrm{O}_{8}$ battery voltages, ionic conductivity, and areal power percent gain.

\begin{tabular}{ccc}
\hline Property & $\mathrm{Li} \| \mathrm{LiFePO}_{4}$ & ${\mathrm{Mg} \| \mathrm{MgS}_{2} \mathrm{O}_{8}}$ \\
\hline Theoretical open circuit voltage (V) & $3.82 \mathrm{a}$ & $4.32 \mathrm{a}$ \\
Flat discharge voltage, V (V) & $3.3 \mathrm{~b}$ & $3.71 \mathrm{c}$ \\
Ionic Conductivity, $\mathrm{K}(\mathrm{mS} / \mathrm{cm})$ & $1.13 \mathrm{~d}$ & $1.27 \mathrm{e}$ \\
$\quad \begin{array}{c}\text { Calculated battery flat discharge } \\
\text { power increase }\left(\mathrm{W} / \mathrm{cm}^{2}\right) \text { as } \%\end{array}$ & $100 \%$ & $142 \% \mathrm{f}$ \\
\hline
\end{tabular}

a-Calculated based on the standard state ion potentials of Baird et al. [7]; b-Observed experimentally (see Ref. [6]); c-Computed value based on the data of Zhu et al. [6] illustrating the flat discharge voltage divided by the theoretical open circuit voltage is 86\%; $\mathrm{d}-\mathrm{Measured}$ in Ref. [6]; e-The ion transference number for $\mathrm{Mg}^{2+}$ was assumed to be $12 \%$ larger, based on the diffusion calculations above, compared to that for $\mathrm{Li}^{+}$. This increase is reflected in the larger ionic conductivity of the $\mathrm{Mg} \| \mathrm{MgS}_{2} \mathrm{O}_{8}$ system; $\mathrm{f}$-Estimated based on data in Ref. [6] and Equation (5) here.

Table 3. A summary of the comparisons between the $\mathrm{Li}_{|| \mathrm{LiFePO}}$ and projected $\mathrm{Mg} \| \mathrm{MgS}_{2} \mathrm{O}_{8}$ battery operation parameters is presented.

\begin{tabular}{|c|c|c|}
\hline Property & $\mathrm{Li}|| \mathrm{LiFePO}_{4}$ & $\mathrm{Mg} \| \mathrm{MgS}_{2} \mathrm{O}_{8}$ \\
\hline Theoretical open circuit voltage (V) & 3.82 & 4.32 \\
\hline Flat discharge voltage $(\mathrm{V})$ a & 3.3 & 3.71 \\
\hline Ionic conductivity (mS/cm) change, $\%$ & $100 \%$ & $112 \%$ \\
\hline Flat discharge power $\left(\mathrm{W} / \mathrm{cm}^{2}\right)$ change, $\%$ & $100 \%$ & $142 \%$ \\
\hline $\begin{array}{l}\text { Weight per mole electron transferred } \\
\qquad\left(\mathrm{g} / \text { mole }^{-} \mathrm{e}^{-}\right)\end{array}$ & 164.6 & 120.4 \\
\hline Specific power $\left(\mathrm{W} / \mathrm{cm}^{2} \cdot \mathrm{kg}\right)$ change, $\%$ & $100 \%$ & $194 \% \mathrm{~b}$ \\
\hline Specific energy stored (MJ/kg) change, \% & $100 \%$ & $154 \% \mathrm{c}$ \\
\hline
\end{tabular}

a-Given as $85 \%$ of theoretical open circuit voltage - this study; b-Calculated using weight per mole electron (g/mole·e ) from this table, and $\mathrm{W} / \mathrm{cm}^{2}$ values from Table 2; c-Calculated using flat discharge voltage (V), ionic conductivity (mS/cm), thickness of membrane (see text), and weights per mole electron transferred $\left(\mathrm{g} / \mathrm{mole}^{-} \mathrm{e}^{-}\right)$from this table. 
Table 3 is because it is more useful to note the percentage gain of a particular property. Hence, by not giving absolute values there is no tie to a particular study, making the comparison more universally valid and helpful.

\section{Conclusion}

The benefits of the $\mathrm{Mg} \| \mathrm{MgS}_{2} \mathrm{O}_{8}$ rechargeable battery here includes inexpensive reagents, known synthetic and fabrication methods, a lessened flammability risk, and substantial gains in specific power (194\%) and specific stored energy (154\%) performances. These issues make the proposed magnesium persulfate rechargeable battery superior to state-of-the-art lithium iron phosphate battery technology in particular and rechargeable batteries as a whole.

\section{Acknowledgements}

Support and encouragement of J. W. is gratefully acknowledged.

\section{References}

[1] Nitta, N. and Yushin, G. (2013) High-Capacity Anode Materials for Lithium-Ion Batteries: Choice of Elements and Structures for Active Particles, Particle \& Particle Systems Characterization. Materials Views, Wiley-VCH, 1-20.

[2] Lee, J., Urban, A., Li, X., Su, D., Hautier, G. and Ceder, G. (2014) Unlocking the Potential of Cation-Disordered Oxides for Rechargeable Lithium Batteries, Science, 343, 519-522. http://dx.doi.org/10.1126/science.1246432

[3] Mohanty, D., Sefat, A.S., Payzant, E.A., Li, J., Wood III, D.L. and Daniel, C. (2015) Unconventional Irreversible Structural Changes in a High-Voltage Li-Mn-Rich Oxide for Lithium-Ion Battery Cathodes. Journal of Power Sources, 283, 423-428. http://dx.doi.org/10.1016/j.jpowsour.2015.02.087

[4] Kennedy, T., Mullane, E., Geaney, H., Osiak, M., O’Dwyer, C. and Ryan, K.M. (2014) High-Performance Germanium Nanowire-Based Lithium-Ion Battery Anodes Extending over 1000 Cycles. Nano Letters, 14, 716-723. http://dx.doi.org/10.1021/nl403979s

[5] Li, X., Liu, J., Banis, M.N., Lushington, A., Li, R., Cai, M. and Sun, X. (2014) Atomic Layer Deposition of Solid-State Electrolyte Coated Materials with Superior High Voltage Cycling for Lithium Ion Battery Application. Energy \& Environmental Science, 7, 768-778.

[6] Zhu, Y., Wang, F., Liu, L., Xiao, S., Yang, Y. and Wu, Y. (2013) Cheap Glass Fiber Mats as a Matrix of Gel Polymer Electrolytes for Lithium Ion Batteries. Scientific Reports, 3, 1-6. http://dx.doi.org/10.1155/2013/958506

[7] Bard, A.J., Parsons, R. and Jordan, J. (1985) Standard Potentials in Aqueous Solution. IUPAC-Marcel Dekker Inc., New York.

[8] Malik, R., Burch, D., Bazant, M. and Ceder, G. (2010) Particle Size Dependence of the Ionic Diffusivity. Nano Letters, 10, 4123-4127. http://dx.doi.org/10.1021/nl1023595

[9] Geankopolis, C.J. (1983) Transport Processes and Unit Operations. 2nd Edition, Allyn and Bacon Inc., Boston.

[10] Hancock, R.D. (1990) Molecular Mechanics Calculations and Metal Ion Recognition. Accounts of Chemical Research, 23, 253-257. http://dx.doi.org/10.1021/ar00176a003 